\title{
25 Research Soure on \\ Landslide in rocks of Jodhpur Group at Masuria Hill in Jodhpur, Western Rajasthan, India: Its causes and threat to significant Georesources
}

\section{Saurabh Mathur}

Suresh Gyan Vihar University https://orcid.org/0000-0003-3770-3132

\section{Sudhanshu}

Suresh Gyan Vihar University https://orcid.org/0000-0003-1616-7393

Suraj Kumar Singh ( $\nabla$ suraj.kumar@mygyanvihar.com )

Suresh Gyan Vihar University https://orcid.org/0000-0002-9420-2804

C.P, Khichi

J.N. Vyas University

S. C. Mathur

J.N. Vyas University https://orcid.org/0000-0002-6269-4656

\section{Research Article}

Keywords: Masuria Hill, Landslide, soft and rigid rock zones, Bedding Parallel Shear Zone, Georesources,

Posted Date: July 15th, 2020

DOl: https://doi.org/10.21203/rs.3.rs-40149/v1

License: (c) (1) This work is licensed under a Creative Commons Attribution 4.0 International License.

Read Full License 


\section{Abstract}

The ever first disastrous landslide at Masuria Hill (MH) damaged many houses and properties on 4th October 2019 in surrounding residential colonies of Masuria area in the Jodhpur city, Western Rajasthan India. Present landslide not only created panic among people but also damaged properties and significant georesources which is a serious concern for future. Geologically, $\mathrm{MH}$ is represented by rhyolite of Malani igneous suite (MIS) of Cryogenian age which is overlain by siliciclastic rocks of Jodhpur Group (JG) of Ediacaran age of Marwar Supergroup (MSG). Landslide occur in horizontally disposed rocks of Umed Bhawan Formation (UBF) of JG. UBF is divided into $4-18 m$ thick clay dominated soft sediments zone with sheet and release joints at the base. It is followed by $24-72 \mathrm{~m}$ thick rigid sand zone having orthogonal jointing. This disposition of soft and rigid pattern of sedimentation of UBF is identified as the key horizons responsible for the landslide with shale horizon as the failure plane. Causes of landslide can be explain based on the model of BPSZ (Bedding Parallel Shear Zone). BPSZ is attributed to three main mechanisms: liquefaction, mass wasting and shear stresses that caused the landslide at $\mathrm{MH}$. Study further reveal that residential area surrounding $\mathrm{MH}$ and other seven hills having similar geological disposition are under great threat to future landslide in Jodhpur. Paper also embodies characteristics of georesources having educational and cultural values which are under great threat to landslide along with appropriate hazard mitigation measures.

\section{Introduction}

Recently, NE part of Masuria Hill (MH) experienced ever first landslide on $4^{\text {th }}$ October 2019 in Jodhpur which damaged significant georesources along with many houses, properties and also injured and killed many people in the Bank colony of Jodhpur city, Western Rajasthan, India (Fig.1). Landslide at MH spread panic among people because of sudden and rapid fall of rock mass is certainly an alarm for future disaster in Jodhpur. Rock mass ranging from dust particles to unusually big boulders of upto $3 \mathrm{~m}$ in size moved down to surrounding residential areas in form of screed debris to polygonal boulders debris under gravity. The geological disposition at $\mathrm{MH}$ is represented by rhyolite of MIS form basement which is followed by rocks of UBF and SSF at the top (Fig.2). The UBF at MH is represented by a coarsening upward siliciclastic cycle. The soft clay zone - rigid sandstone zone of UBF played an important role in landslide (Fig. 3). The physical action on rocks of two zones since Ediacaran period yielded several structural elements (Davis, et al., 2012) which lead to provide weaker planes to siliciclastic sequence at $\mathrm{MH}$. Under this geological scenario present paper discusses stratigraphic set up of UBF and its significant georesources which are under great threat to damage. Further, the causes of landslide are explained utilizing model of BPSZ (Bedding Parallel Shear Zone) and also suggests mitigation measures to protect significant georesources, properties and people of Jodhpur residing in surrounding areas of hilly landscape of UBF. Additionally, present study also identified seven similar hills of UBF and surrounding residential areas which are under great threat to landslide in future.

The outcrops of UBF of basal Jodhpur Group (JG) occur mainly at Masuria, Udai Mandir, Kabir Nagar, Pratap Nagar, Mehrangarh hill, Gol Nadi hills along fort road, Ganesh Bhakhri hill in Jodhpur (Fig.3). 
Stratigraphically, 220m thick UBF at its type area at Ganesh Bhakhri hill overlies the Malani Igneous Suite of rocks (745 to $681 \mathrm{Ma}$ ) and underlies the Soorsagar Formation (SSF) of Ediacaran age belonging to JG of MSG. At MH, about $90 \mathrm{~m}$ thick coarsening upward UBF is represented by shale at the base followed by silty shale and shaley siltstone (Clay dominate zone); fine grained, medium grained, coarse-grained sandstone and pebbly sandstone at the top (rigid sandstone zone; Fig.4; Plate 1a, b and c). Dominantly preservation of trough and festoon cross-bed in UBF indicate a deltaic environment (Mathur et al., 2019a \& b). SF displays fine and medium-grained sandstones which occupy the top of $\mathrm{MH}$. It has been found that the distribution and deposition of sediments of $\mathrm{JG}$ at $\mathrm{MH}$ is governed by the configuration of basement rock exposed in the foot hills of $\mathrm{MH}$.

\section{Rhyolite Basement}

Voluminous rhyolite occurs in subsurface of all surrounding residential areas of $\mathrm{MH}$ and its outcrops on surface can also be found along the road from Akhaliya circle to New Kohinoor Cinema Hall and on the road that goes to Veer Durga Das Park, at and around Ram Dev temple and Masuria colony (Fig.1). The distribution of these outcrops clearly indicate that residential colonies, roads and other infrastructures were developed by destroying vast rhyolite georesources having remarkable and significant features (Mathur et al., 2017). At MH, the hard, tough and brown colored rhyolite display fine-grained texture with numerous small rounded to elliptical vesicles on its surface (Plate 1d). Petrographic study indicates that Masuria rhyolite is composed of quartz, feldspar, biotite and iron oxide of extremely fine-grained in nature with few small sized feldspar phenocrysts (Plate 1e).

\section{Rocks of UBF}

UBF forms a coarsening upward sequence at $\mathrm{MH}$ which is represented by shale at the base followed by silty shale, shaley siltstone, fine grained sandstone, medium grained sandstone, coarse grained sandstone and pebbly sandstone at the top. JG at MH is distinctly divided into three zones in chronological order; (i) clay dominated soft sediment zone at the base and (ii) sand dominated rigid zone in middle (Plate 1c) and rigid zone of rocks of SSF at the top (Fig.4). Soft zone is showing gradational contact in sedimentation is represented by shale in contact with rhyolite at base and followed by silty shale and shaley silt stone (Plate $1 \mathrm{f}$ and $\mathrm{g}$ ). The shale is extremely fine-grained rock, dominantly composed of clay minerals, few silty quartz and iron oxide. The soft zone has sheet and release joints. The increasing amount of silt size detritus grades it to silty shale and shaly siltstone at the top. The shaley siltstone grades upward into fine grained sandstone followed by medium grained, coarse-grained (Plate $1 \mathrm{~h}$, and i) and pebbly sandstone at the top constituting the rigid sandy zone of $\mathrm{MH}$. The sandstones of rigid zone have orthogonal joints with varied spacing and are highly fractured. The sandstones of rigid zone are dominantly composed of mono-crystalline sub-angular to sub-rounded clastic quartz grains devoid of feldspar and are cemented by iron oxide. With same mineralogical composition, only the textural differences make the four facies of the sandstone. The top of $\mathrm{MH}$ is marked by fine to medium grained sandstone of SSF constituting the rigid zone.

\section{Georesources of Masuria Hill}




\section{Georesources in Rhyolite}

Basement rhyolite of $\mathrm{MH}$ is belonging to MIS which is world's third and India's first largest, felsic and terrestrial igneous province represent 'Pan-African orogeny in this part of India of Gondwana land (Bhushan, 2000; Maheshwari et al., 2009) indicating its international significance. Rhyolite at MH showcase basement cover relationship through interface between MIS (rhyolite) and overlying JG (shale of UBF). Being rare among the vast outcrops of $\mathrm{JG}$, this non-conformity between sedimentary and volcanic rocks was declared as national geological monument (GSI, 2001). This rare outcrop is of sequence stratigraphic significance. Beside all these features, text book style vesicular structure, porphyritic structures (Plate 1d and e), onion-shell weathering structures and beautiful flow structures in rhyolite impart spectacular view to the outcrop specially at Masuria temple (Fig.1). This outcrop can be an excellent outdoor museum with remarkable features of great educational values for students and researchers.

\section{Georesources in rocks of UBF}

Coarsening upward siliciclastic sequence of deltaic environment displaying gradational contacts between rocks of UBF is an ideal outcrop (Plate 1a, b, and c). This sequence also preserve spectacular and text book style sedimentary structures like laminations, beddings graded bedding, chromatographic structures; festoon, planar and trough cross bedding (Plate 2a, b, c, d and e) making UBF, a significant Georesource of regional to national significance. Outcrops at Veer Durga Das Park (Fig.1) can be an excellent outdoor field museum of great educational values with all these structures and features.

\section{Historical and Cultural Georesources}

Land of Marwar is rich in history, culture and tradition with numerous heroes by it which inspires the whole world with their bravery, velour and sacrifices (Singh and Mathur, 2014). One such person of Marwar is Veer Durga Das Rathore. He is credited for having saved the regime of Rathore Dynasty following after the effects of the death of King Jaswant Singh in the year 1678. In his memory, an equestrian statue has been erected (Plate 2f) through the efforts of Chief Patron Maharaja Gaj Singh ji of Veer Durga Das Smriti Samiti, Jodhpur and with the help of Rajasthan Government. This Statue unveiled by the then Prime Minister of India Mr. Atal Bihari Vajpayee on October 3, 1998. to respect him, a stamp was also unveiled by central government indicate he was respectful personality of India. Similarly, Veer Durga Das Rathore Memorial Award is also given every year on his birth anniversary to people contributing to the welfare of society in various fields. One of the authors (SCM) got this prestigious award in year 2014 for his outstanding research work in the field of geology of Marwar. Earlier, to convert this hill into a synoptic tourist destination, Shri Mathura Das Mathur, the then education minister had initiated and planned to make $\mathrm{MH}$ an attractive tourist place in his period. Later on, project was extended by the efforts of Mr. Jagat Singh ji of Durga das Samiti. Presently, it is a beautiful historical and cultural monument of Jodhpur with big statue of Durga Das, museum, library, lush green garden with restaurant, open air theater, musical fountain, facilities for sports for children and entertainment for local people and visitors (www.aapnojodhpur.com/veer-durgadas-rathore). All these geological, historically and culturally 
significant georesources occur in thirteen hectors of area at $\mathrm{MH}$. There are many other culturally significant georesources at similar six more hilly areas of UBF which are under great threat to landslide. Hence, the understanding of causes of landslide at $\mathrm{MH}$ would be of great help to suggest mitigation measures.

\section{Causes of land slide at MH}

It is clear from geological attributes that $\mathrm{MH}$ has hard-soft-hard (rhyolite-clay-sand) depositional sequence from basement to top of UBF and this sequence has not been tectonically deformed. Among structural elements, mainly joint patterns have played a crucial role in weakening the rocks of UBF. Further, it is observed that soft sediments (shale, silty shale and shaley siltstone) dominantly have sheet and release joints which are formed near the surface. These joints formed due to effect of frequent exposures of soft rocks to diurnal temperature cycle in summer. As a result of which rocks were heated, expanded and stressed in day time; cooled and contracted at night and finally became relaxed elastically. This repeated physical action built up stresses that eventually exceed the tensile strength of the bedrock. Further, compressive stresses are released either along pre-existing structural elements such as bedding planes and cleavage i.e. planar and platy minerals (Davis, et al., 2012) present in clay zone of MH. Repetition of this process resulted into the formation of sheet and relaxed jointing in clay zone. Similarly, in rigid zone, this physical action of diurnal thermal cycling creates stresses in clastic grains of sandstone (being more brittle) which leads to fracturing the rock, whose one set (vertical) is persistent and abut at soft sediment surface to make T intersections (Pollard and Aydin, 1988). This fracturing pattern produced orthogonal jointing dividing the rigid sandstone into characteristic blocks. The jointing pattern and varied spacing between two consecutive joints determine the size and shape of the resulting blocks i.e. sometime closed and sometime large space between joints (Plate 1c), produced pebbles to boulder size blocks which destructed the properties in the Bank colony (Plate 1a, $2 \mathrm{~g}, \mathrm{~h}, \mathrm{I}$ and k). Under this physical scenario of rocks with two zones at $\mathrm{MH}$, the causes of Masuria landslide can further be explained by model of BPSZ (Bedding Parallel Shear Zone). BPSZ (Girty, 2009) at MH attributed to three main mechanisms: liquefaction, slumping (mass wasting) and shear stresses exerted by the flow of material during land slide.

\section{Liquifaction}

Liquifaction occured at MH due to coherent mass of loosely consolidated materials (soft zone) and a rock layer moved a short distance along a planar surface i.e. various joints and also bedding planes. Additionally, at MH permeable layer (sand zone) overrides an impermeable surface (clay zone) which leads to block slumps along planar surface in which one or more related block units move down slope as a relatively coherent mass. Rains also provide lubrication for the material to slide by increasing pore pressure. Instabilities are caused by density contrasts and also by movement of pore water and rain water infiltration through the sediments. It is also corroborated that Jodhpur shows increasing trend of rains since last decade and received six times more rainfall in monsoon season of 2019 (www.weatherind.com > India > Jodhpur). 


\section{Slumping (mass wasting)}

After liquefaction, slumps frequently occur due to the removal of a slope base by natural physical processes. Slump at MH took place due to mass wasting that occurs when a coherent mass of loosely consolidated clay zone and rigid sandstone moves a short distance down a slope. It is due to erosion that results in the mass movement of rock blocks, soil and debris down a slope in form of rock slides, debris flows and earth flows.

\section{Shear stresses during flow of material}

During slumping, detachment of sandstone blocks at MH occurs when stresses imposed become greater than the strength of the clay zone to hold them in place. Further, under the influence of gravity, the blocks were mobilized when the shear stress imposed on a surface exceeds the shear strength. It resulted into the fall of a range of material from clay-sand size to large boulders on the houses below from the cliff like face of MH in Bank colony and damaged houses, properties and significant georesources (Plate 1a, 2 $\mathrm{g}, \mathrm{h}, \mathrm{l}$ and $\mathrm{k}$ ).

\section{Results And Discussion}

Spectacular and isolated hillock of Masuria (Fig.1) is amid from surrounding plane area to attain a height of $145 \mathrm{~m}$. It is a popular place of Jodhpur for tourists and local people. Since, many residential colonies have been developed legally and illegally around foot hills and also on it are under great threat in future as evident by present landslide. Significantly, under present study, the soft clay zone (mainly shale horizon) is identified as failure plane and fall of large boulders-cobbles from rigid sand zone were responsible for damage as per the model of BPSZ discussed above. Present study also found that two such critical zones are spread all along the $1.81 \mathrm{~km}$ peripheral area surrounding $\mathrm{MH}$. Hence, all colonies on peripheral area of $\mathrm{MH}$ are under great threat to landslide in future viz a viz significant georesources. Since, landslide has been initiated at $\mathrm{MH}$ which is situated in the heart of city, many human activities in the surrounding would lead to aggravate the landslide in future. These factors are mainly: earthwork and construction of buildings; vibrations from machinery and traffic, blasting for breaking and removing rocks leads to disturb the natural disposition of rock sequences of $\mathrm{MH}$ especially soft clay zone. Additionally, present landslide occurred when Jodhpur received $30 \%$ more rain fall in year 2019 along with access rainfall in the first week of September 2019 (www.weather-ind.com, jodhpur) which may have aggravated the process of liquefaction and erosion at $\mathrm{MH}$. Evidently, during same period small scale landslide occurred at hillock with same rock disposition of UBF at Uday Mandir area in Jodhpur (Fig.4) which killed three persons and many were injured. Hence, these two evidences are an alarm for future disaster. Similarly, the residential areas around seven hills of UBF i.e. Masuria hill, Udai Mandir hill, Kabir Nagar hill, Pratap Nagar hill, Mehrangarh hill, Gol Nadi hill along fort road, Ganesh Bhakri hill ( $2, \mathrm{l}, \mathrm{m}, \mathrm{n}$ and o) as shown in Fig. 4 are high risk zones for landslide and should be declared as a landslide prone zone in Jodhpur to save properties, people and significant georesources.

\section{Mitigation Measures}


Landslide in rocks of UBF can be mitigated by both passive and active mitigation tools. Looking to the geological disposition and nature of rocks of UBF, Passive mitigations can be done by using drape nets, rock - fall catchment fences and by constructing diversion dams as generally utilized in landslide prone areas (Rai et al., 2014). These are preferable and tend to be more sustainable. The active mitigations require human intervention to operate properly and can be done by using rock bolting, slope retention systems and shotcrete. These are usually applied based on character and location of rocks (Habibah et al., 2011). Accordingly, local administration should take serious cognizance on the $4^{\text {th }}$ Sept, 2019 disaster of the ever first landslide at $\mathrm{MH}$ by adopting suggested mitigation measures to avoid such future disasters in the Jodhpur city.

\section{Conclusion}

The ever first land slide on $4^{\text {th }}$ October, 2019 at $\mathrm{MH}$ is a serious alarm for Jodhpur for future disaster due to landslide. Sedimentation and disposition of soft and rigid pattern of UBF and clay zone is identified as key horizons and shale as failure plane for landslide at $\mathrm{MH}$. Present study found that the causes of landslide of MH can be explained by model of BPSZ (Bedding Parallel Shear Zone) attributed to liquefaction, slumping (mass wasting) and shear stresses mechanism. $1.81 \mathrm{~km}$ peripheral area surrounding $\mathrm{MH}$ is critically very susceptible and under great threat to landslide in future along with surrounding residential colonies of other six hillocks having similar rock disposition of UBF in Jodhpur. Landslide at $\mathrm{MH}$ not only damaged the houses and properties but also destructed the significant georesources. Importantly, the igneous and sedimentary georesources of $\mathrm{MH}$ along with six other hills are under threat which are of great educational and cultural values of national and international significance and need urgent protection. These can be protected and conserved by applying suggested mitigation measures.

\section{Declarations}

\section{Compliance with Ethical Standards:}

Funding: This study was funded by Suresh Gyan Vihar University

Conflict of Interest: Authors declares that he/she has no conflict of interest.

Ethical approval: This article does not contain any studies with human participants or animals performed by any of the authors.

Consent:

Photographs in the Supplmental Figures were taken by the authors and consent from all individuals has been taken and that they agree to have their images included in the paper

\section{References}


1. Bhushan, S.K. 2000. Malani rhyolite: a review. Gondwana Research., 3:65-77

2. Davis, G.H., Reynolds, S.J., Kluth, C. 2012. Structural Geology of Rocks and Regions (3rd ed.): John Wiley and Sons, Inc., New York, 864

3. Girty, G.H. 2009. Landslides (PDF), Perilous Earth: Understanding Processes Behind Natural Disasters, Montezuma Publishing, 1-17.

4. GSI, 2001. Monuments of Stratigraphic Significance, Malani volcanics overlain by Jodhpur sandstone Memmo. Geological Survey of India. Retrieved 2009-03-23.

5. Habibah, L., Muqtada, M., Khan, A., Jefriza. 2011. Monitoring of shallow landslide in Tun Sardon 3.9 km Pinang Island, Malaysia. International Journal of the Physical Sciences., 6(12):2989-2999

6. Maheshwari, , Coltorti, M., Rajput, S.K., Verma, M. 2009. Geochemical characteristics, and petrogenesis of Neoproterozoic peralkaline granites, Barmer District, SW Rajasthan. India International Geology Review., 51(12): 1103-1120

7. Mathur, S.C., Pradip, K., Mathur, S. and Rathore, S.S. 2017. Neoproterozoic -Ediacaran Mehrangarh Ridge of city, W. Rajsathan, India: its Geoheritage and Geotourism sites. Proceeding, Geopark conference, Tai Pei, Taiwan (Abstract).

8. Mathur, S.C., Parihar, V.S., Ram, H., Mathur, S. 2019 a. Stratigraphic and Investigation of Ediacaran Jodhpur Group in and around Jodhpur City, India, Estudios Geologicos, Spain., 75(2):20-22

9. Mathur, S., Sudhanshu, Singh, S.K., Mathur, S.C. 2019b. Ediacaran Fauna of the Jodhpur Group (Marwar Supergroup) in Jodhpur city, Western Rajasthan, India:Implication for potential Geoheritage Sites, Estudios Geologicos, Spain, 75(2):1-4

10. Pollard, D.D. and Aydin, A. 1988. Progress in understanding jointing over the past century, Geological Society of America Bulletin., 100:1181-1204

11. Rai, P.K., Mohan, K., Kumar, V.K. 2014. Landslide hazard and its mapping using remote sensing and GIS. Journal of Scientific Research., 58:1-13

12. Singh, Shiv., and Mathur, S.C. 2014. Journey of Jodhpur city since its foundation through water impounding structures. In: K.L.Shrivastava and P.K.Srivastva (ed) Frontiers of Earth Science, Scientific Pub. (India), pp 527 - 550

\section{Plate Description}

\section{Plate 1.}

a. Outcrop of coarsening upward siliciclastic facies of UBF at MH. 
b. The horizontally disposed soft clay zone and rigid sand zone of UBF at MH.

c. Soft clay zone showing sheet and release joints while rigid sand zone showing orthogonal jointing of varied spacing in UBF.

d. Fine grained rhyolite showing numerous small rounded to elliptical vesicles.

e. Thin section of Rhyolite showing laths of feldspar and biotite in extremely fine grained quartzofeldspathic matrix. Crossed Nicols.10X.

$f$. Thin section of shale showing extremely fine-grained matrix of clay minerals with few silt size quartz and feldspar with iron oxide cement. Crossed Nicols.10X.

g. Thin section of shaley siltstone showing extremely fine-grained silt size quartz and feldspar in groundmass of clay minerals and iron oxide. Crossed Nicols.10X.

h. Outcrop of sandstones of rigid zone showing fracturing and jointing.

i. Thin section of coarse sandstone showing monocrystalline sub angular to sub-rounded quartz and few felspar grains set in cement of clay and iron oxide minerals.

\section{Plate 2.}

a. Beautiful laminations and beds in fine grained sandstone of UBF.

b. Coarse to medium grained sandstone of UBF showing graded bedding.

c. Fine grained sandstone of UBF showing planar cross bedding.

d. Medium grained sandstone of UBF showing well preserved trough cross bedding.

e. Medium grained sandstone of UBFshowing beautiful chromatographic structures.

$\mathrm{f}$. Veer Durga Das Rathore Park of $\mathrm{MH}$ of historical and cultural heritage values.

g-k. Damage to the houses and property of people due to landslide Note: Bigger sized sandstone boulders and cobbles along with sand to pebble size of rock material that fall showing severity of landslide at $\mathrm{MH}$.

I- o. Field photographs showing similar to $\mathrm{MH}$ landslide prone area and rock disposition of hills in different part of Jodhpur

\section{Figures}




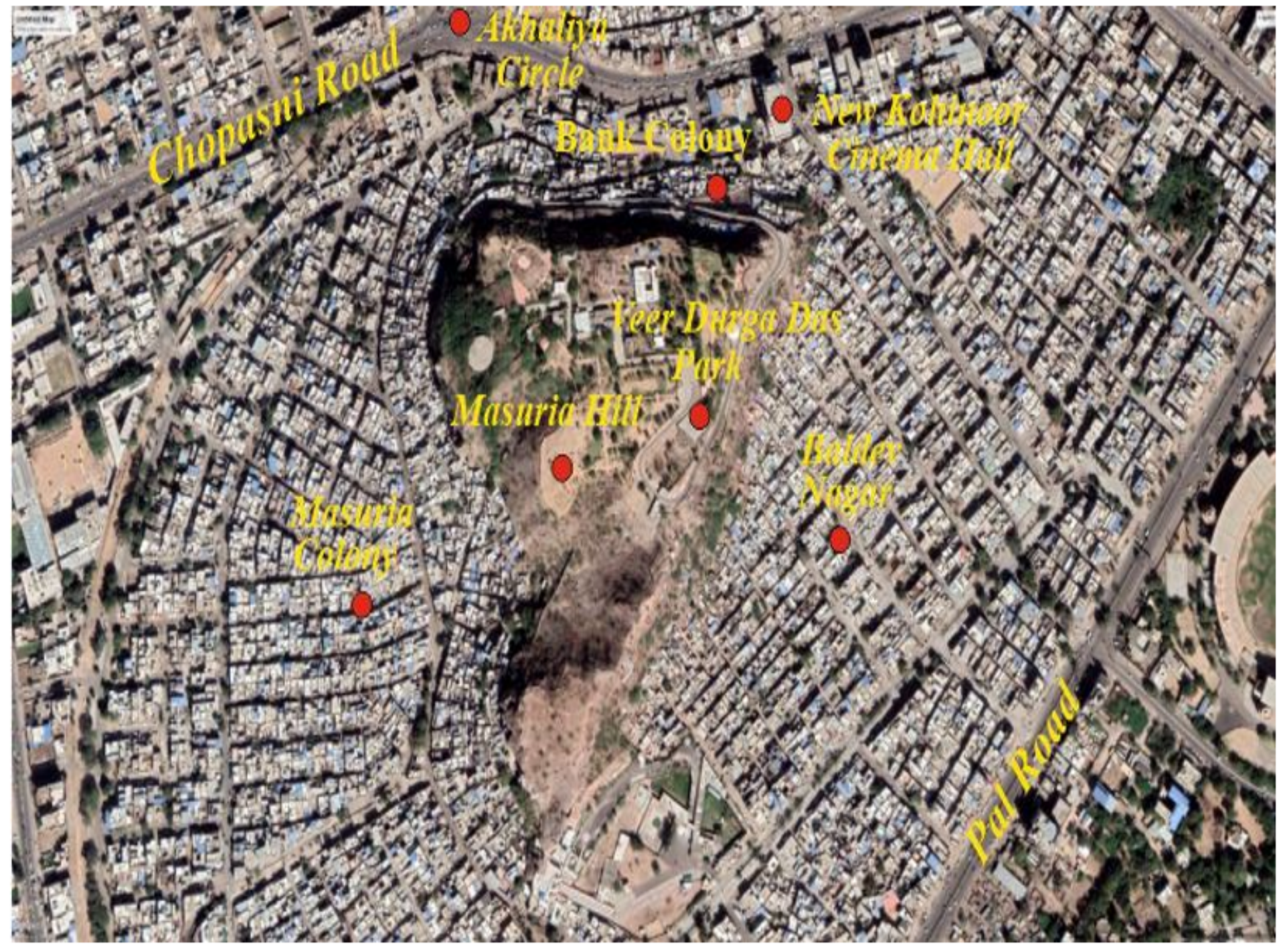

Figure 1

Google image showing location of Masuria Hill and surrounding residential area. 


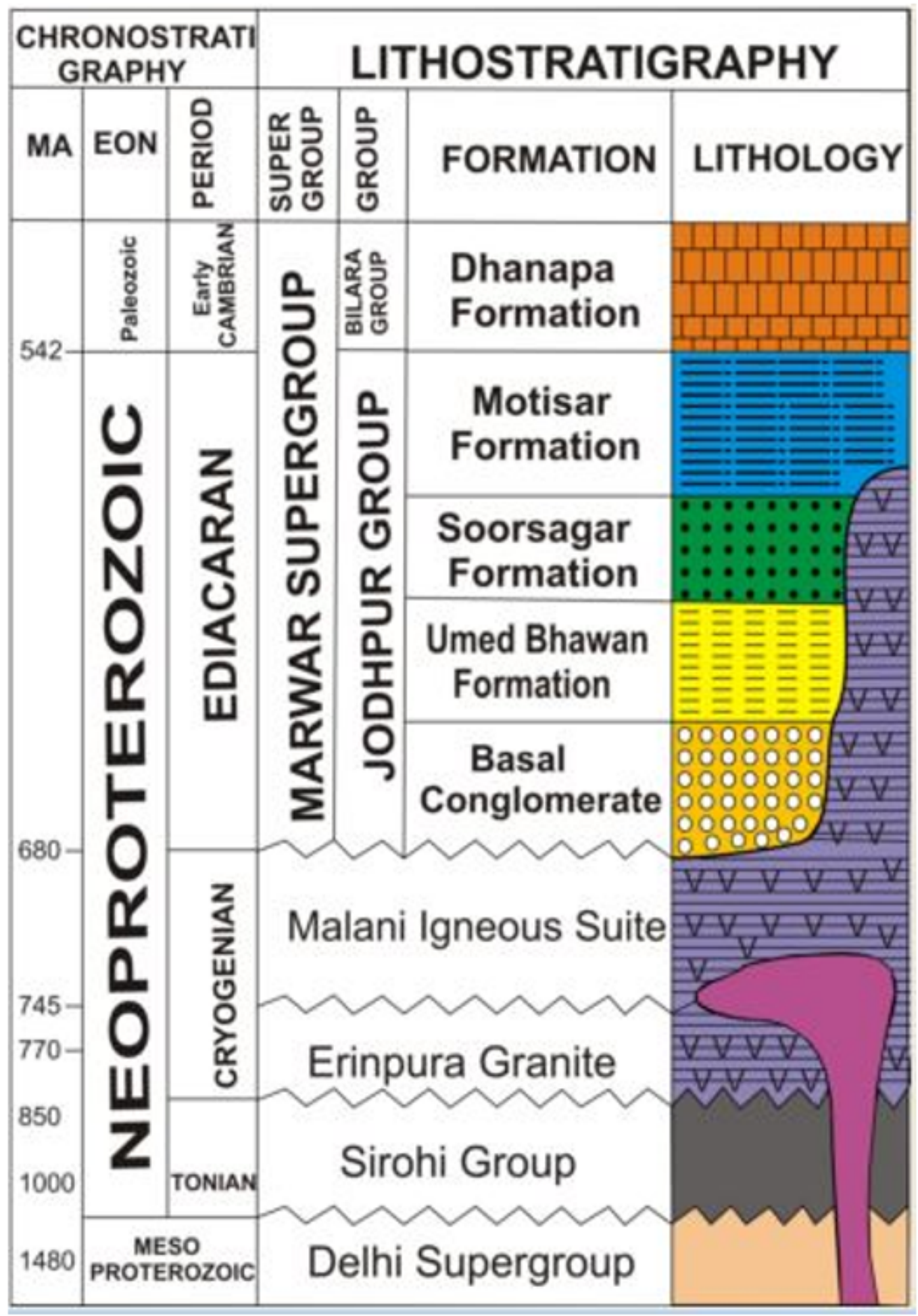

Figure 2

Lithostratigraphy of Jodhpur Group of study area (Mathur et al., 2019a). georesources, properties and people of Jodhpur residing in surrounding areas of hilly landscape of UBF. Additionally, present study also identified seven similar hills of UBF and surrounding residential areas which are under great threat to landslide in future. 


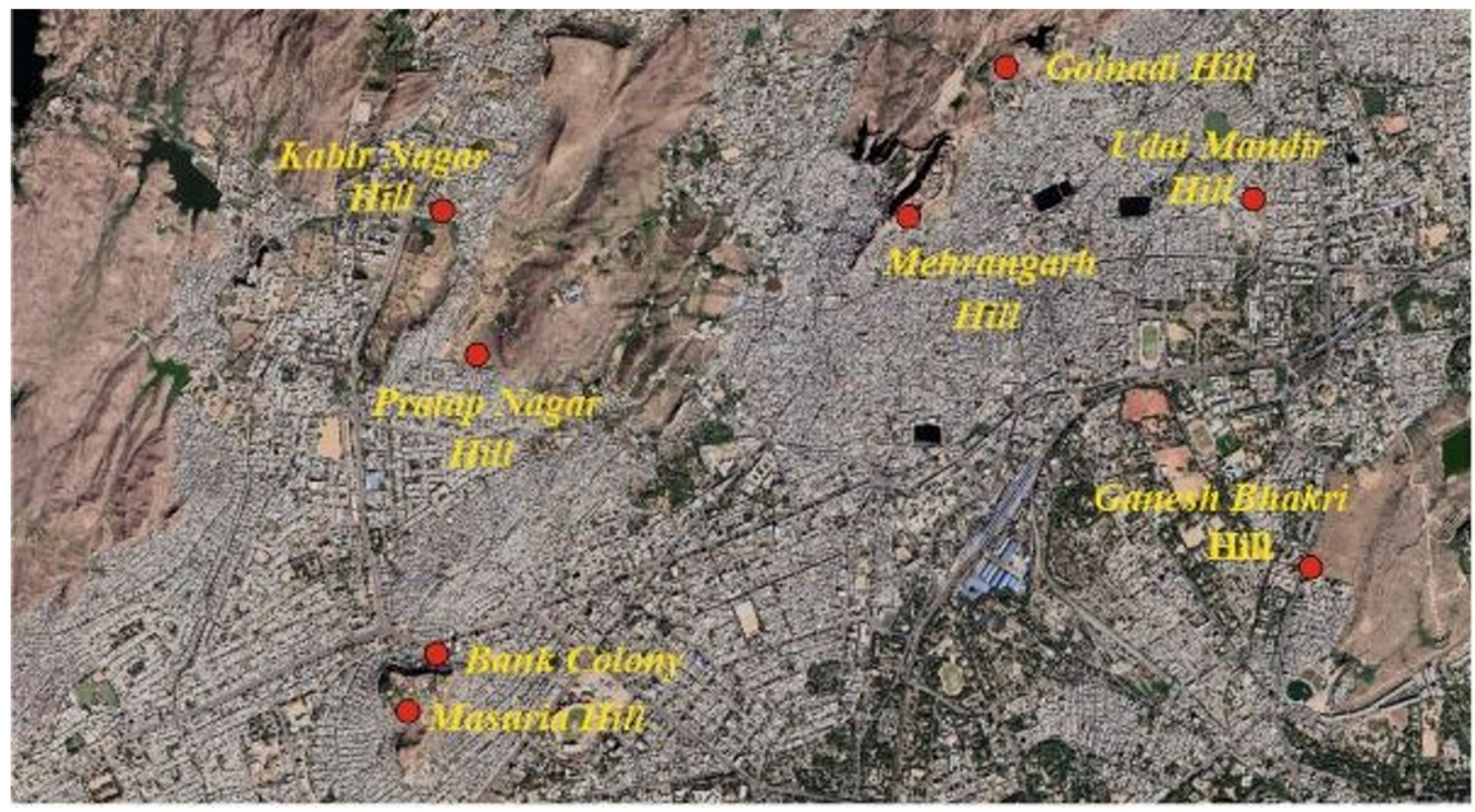

\section{Figure 3}

Google image showing landslide prone hills and residential areas in Jodhpur 


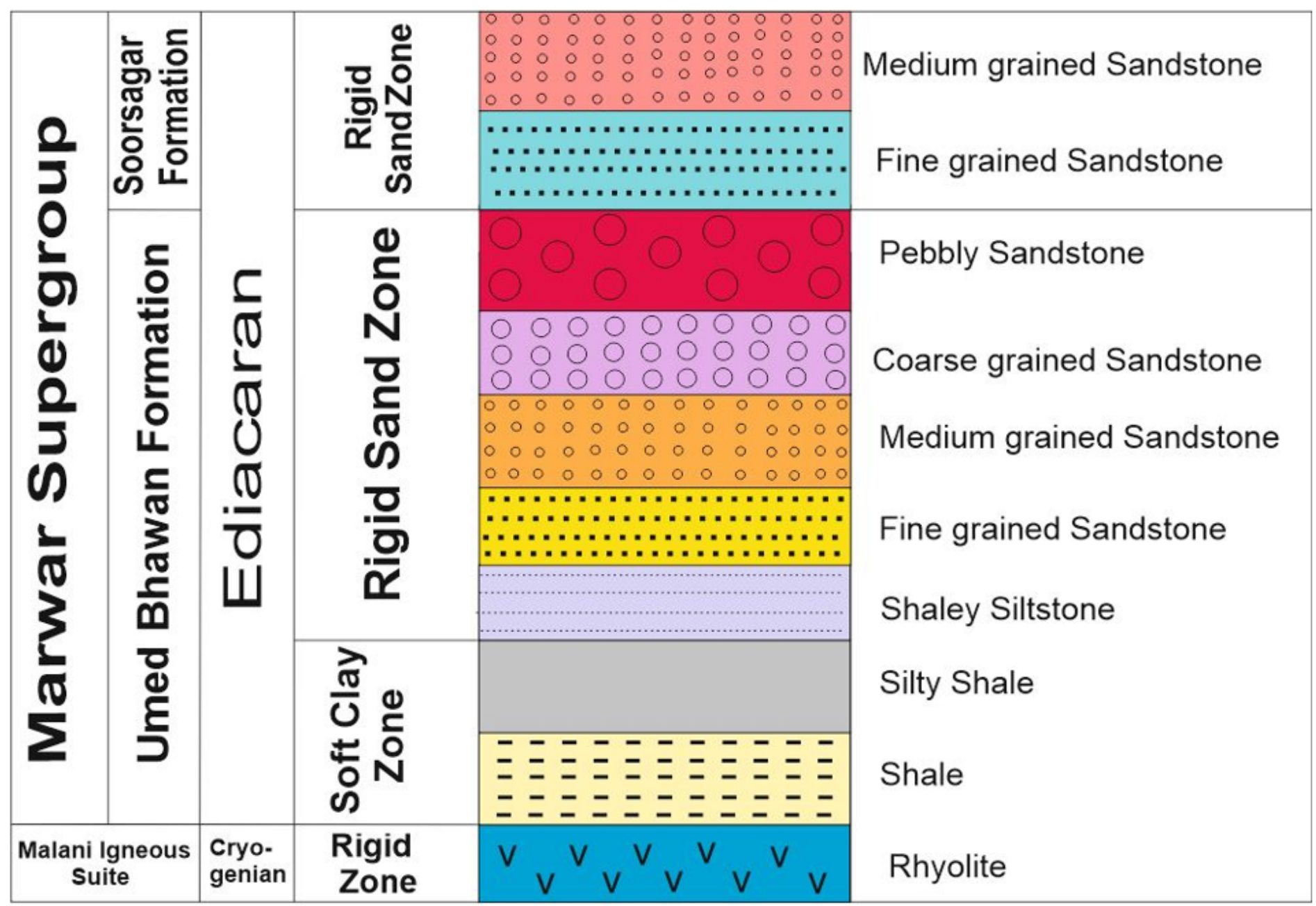

Figure 4

Generalized lithostratigraphy of JG at MH showing distribution of soft and rigid zones.

\section{Supplementary Files}

This is a list of supplementary files associated with this preprint. Click to download.

- PlateMH.docx 